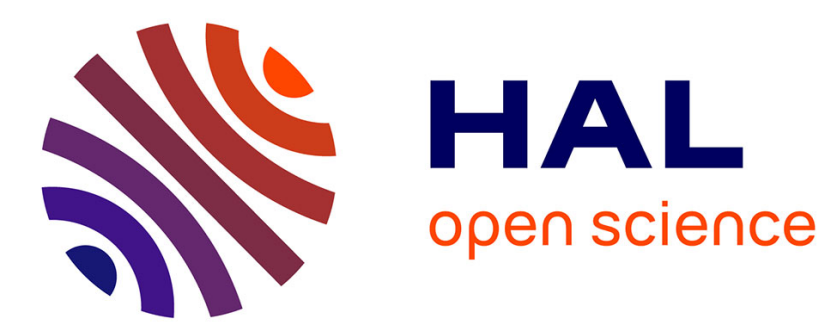

\title{
Superplurals in English
}

\author{
Oystein Linnebo, David Nicolas
}

\section{To cite this version:}

Oystein Linnebo, David Nicolas. Superplurals in English. Analysis, 2008, 68 (299), pp.177-269. 10.1111/j.1467-8284.2008.00737.x . ijn_00175619v3

\section{HAL Id: ijn_00175619 \\ https://hal.science/ijn_00175619v3}

Submitted on 3 Dec 2007

HAL is a multi-disciplinary open access archive for the deposit and dissemination of scientific research documents, whether they are published or not. The documents may come from teaching and research institutions in France or abroad, or from public or private research centers.
L'archive ouverte pluridisciplinaire HAL, est destinée au dépôt et à la diffusion de documents scientifiques de niveau recherche, publiés ou non, émanant des établissements d'enseignement et de recherche français ou étrangers, des laboratoires publics ou privés. 


\section{Superplurals in English}

Øystein Linnebo and David Nicolas

\section{Plurals, superplurals and their philosophical significance}

It is now widely believed among philosophers and logicians that ordinary English contains plural terms and plural predicates. For instance,

(1a) Alice, Bob and Charlie cooperate

should be seen as having the logical form

(1b) $\quad F(a a)$

where ' $a a^{\prime}$ ' is a plural term, and ' $F$ ' a plural predicate. Following George Boolos (1984) and others, many philosophers and logicians also think that plural expressions should be analysed as not introducing any new ontological commitments to some sort of 'pluralentities', but rather as involving a new form of reference to objects to which we are already committed (for an overview and further details, see Linnebo 2004). For instance, the plural term ' $a a$ ' refers to Alice, Bob and Charlie simultaneously, and the plural predicate ' $F$ ' is true of some things just in case these things cooperate.

A natural question that arises is whether the step from the singular to the plural can be iterated. Are there terms that stand to ordinary plural terms the way ordinary plural terms stand to singular terms? Let's call such terms superplural. A superplural term would thus, loosely speaking, refer to several 'pluralities' at once, much as an ordinary plural term refers to several objects at once. ${ }^{1}$ Further, let's call a predicate superplural if it can be predicated of superplural terms.

It is reasonably straightforward to devise a formal logic of superplural terms, superplural predicates, and even superplural quantifiers (see Rayo 2006). But does this formal logic reflect any features of natural languages? In particular, does ordinary English contain superplural terms and predicates? The purpose of this article is to address these questions. We examine some earlier arguments for the existence of superplural expressions in English and find them to be either

\footnotetext{
${ }^{1}$ This is only loosely speaking, as one need not be committed to such entities as pluralities over and above the objects in question considered simultaneously.
} 
inconclusive or not sufficiently far-reaching. Then we present some better examples of the superplural in ordinary English.

Our question about the existence of superplural expressions in English and other natural languages is obviously important to linguistics and the philosophy of language. Less obviously, the question is also important to philosophical logic and philosophy more generally. The reason is as follows. The discovery of plural expressions has led to the development of a plural logic, which extends ordinary first-order logic by adding plural variables, plural predicates, and plural quantifiers that bind plural variables (Boolos 1984, Linnebo 2004). Plural logic appears to have some very attractive features, and this has made it an extremely popular tool in philosophical analysis. Since plural quantifiers are logically just like second-order quantifiers over monadic (or one-place) concepts, plural logic has the expressive and deductive power of monadic secondorder logic. But unlike second-order logic with its vast ontology of concepts (or classes or other 'second-order entities'), plural logic does not seem to be committed to any new entities over and above the objects that its ordinary singular quantifiers range over. ${ }^{2}$

However, plural logic is also more limited than traditional higher-order logic. One uncontroversial limitation of plural logic is that there is no (primitive) plural counterpart of quantification over relations (that is, of concepts taking more than one argument). But this limitation can be overcome if ordered pairs are available; for quantification over relations can be simulated by plural quantification over ordered pairs. A second alleged limitation is that there is no plural counterpart of quantification over second- and higher-level concepts (where a concept of one level takes as arguments concepts of the level immediately below). If real, this limitation could not easily be overcome. However, this purported limitation is highly controversial. Some theorists believe there are higher-level versions of plural logic with the same virtues as ordinary plural logic, while other researchers disagree. ${ }^{3}$

How can this matter be settled? Both parties agree that a sufficient condition for the legitimacy of a form of quantification is its presence in English or some other natural language. So if our arguments in this article are correct, this goes some way towards justifying a superplural logic, expressively and deductively equivalent to monadic third-order logic. And this suggests that further extensions may be legitimate as well. ${ }^{4}$

\footnotetext{
2 This alleged ontological innocence of plural quantification is a matter of some controversy. See Linnebo 2004 for references and a survey of the debate.

3 See Hazen 1997, Linnebo 2003 and Rayo 2006 for the former view, and McKay 2006: 46-53 and 137-139 and Uzquiano 2004 for the latter.

${ }^{4}$ However, this need not be the only way of settling the matter. In particular, it is controversial whether the above condition for the legitimacy of a form of quantification is necessary. This is denied by Hazen 1997, Linnebo 2003 and Rayo 2006, who pursue alternative defences of higher-level versions of plural logic.
} 


\section{Plural expressions in English}

Before we start looking for superplural expressions in English, it will be useful to review some of the evidence that has been given for the existence of ordinary plural expressions.

One way in which predicates can be classified is in terms of the number of their argument places. For instance, the predicate ' $x$ is hungry' takes one argument, and ' $x$ loves $y$ ' takes two. But as has long been realized (cf. Leonard and Goodman 1940, Oliver and Smiley 2004), some predicates can take different numbers of arguments at the same argument place. The verb 'cooperate' is a case in point:

(2a) Alice and Bob cooperate.

(2b) Alice, Bob and Charlie cooperate.

(2c) Alice, Bob, Charlie and David cooperate.

In these sentences, two, three and four arguments occur at what looks like the same argument place. Let's call such predicates multigrade.

Some multigrade predicates are such that any predication based on one of them is analytically equivalent to a sentence involving only ordinary predications with one argument at each argument place. Consider for instance

(3a) Chirac and Sarkozy are French.

This sentence is analytically equivalent to

(3b) Chirac is French and Sarkozy is French.

More generally, say that a predicate $P$ is distributive just in case the predication $P\left(a_{1}\right.$ and $\ldots$ and $\left.a_{n}\right)$ is analytically equivalent to the conjunction $P\left(a_{1}\right) \& \ldots \& \mathrm{P}\left(a_{n}\right)$. Perhaps a predication based on a distributive predicate can be analysed in terms of the associated conjunction of ordinary predications. Let's call this the conjunctive analysis.

We need not answer the question whether the conjunctive analysis of (3a) as (3b) is acceptable. For present purposes, it suffices to observe that there are many non-distributive multigrade predicates for which this kind of conjunctive analysis is obviously unavailable. For instance, on its most natural reading ( $2 b)$ is not analytically equivalent to 
Alice cooperates, Bob cooperates and Charlie cooperates.

Multigrade predicates thus pose a challenge to logicians and semanticists: How are they to be analysed? The analysis that is currently most popular among philosophers and logicians is in terms of plural predication (McKay 2006, Oliver and Smiley 2004, Yi 2005). ${ }^{5}$ For instance, the sentences (2a) - (2c) are taken to involve the same plural predicate, namely ' $x x$ cooperate', where the argument place ' $x x$ ' can be any plural argument (such as 'Alice and Bob' and the other plural arguments involved in the above sentences). A plural argument may refer to several things at once. A plural predication then says that a given plural predicate is satisfied by those things that are referred to severally by its plural argument. This motivates the following principle.

(P) Multigrade predicates are plural predicates.

Once we have established the existence of some plural terms and plural predicates, we can go on to find more such expressions. For instance, (3a) too should presumably be seen as consisting of a plural term and a plural predicate, as this seems to provide the best explanation of the well formedness of similar sentences with more complex predicates, such as the following sentence:

(3c) Chirac and Sarkozy are French and cooperate.

\section{Searching for superplurals: earlier proposals}

In this section we discuss some earlier attempts to establish the existence of the superplural in ordinary English. We point out some shortcomings of these attempts. In the next section we present what we take to be some better examples of the superplural.

The following sentence (inspired by Oliver and Smiley 2005: 1062) appears to provide an example of a superplural term:

\footnotetext{
5 This is not true of linguistics, where plural logic is less well known. The popular analyses in linguistics are in terms of sets, mereological sums or events. For a representative sample, see Schwarzschild 1996, Link 1998 and Landman 2000. However, the analyses in terms of sets and events threaten to be inconsistent when one allows quantification over absolutely everything (Rayo 2002 and Rayo and Uzquiano 2006, but see also Schein 2006). And the analysis in terms of mereological sums is widely assumed to be inadequate (but see Nicolas, manuscript).
} 
(4a) Russell and Whitehead, and Hilbert and Bernays are joint authors of multivolume treatises on logic.

For it seems that in (4a) the term 'Russell and Whitehead, and Hilbert and Bernays' denotes two twosomes and thus is superplural. However, it is not clear that (4a) actually requires a superplural analysis, as (4a) is analytically equivalent to the following sentence without any superplural expressions:

(4b) Russell and Whitehead are joint authors of multi-volume treatises on logic, and Hilbert and Bernays are joint authors of multi-volume treatises on logic.

This means that (4a) may lend itself to a conjunctive analysis that uses only ordinary plural expressions. As in the case of the conjunctive analysis of (3a) as (3b), we need not answer the question whether (4b) is actually an acceptable analysis of (4a). Our claim is just that this purported example of a superplural term fails to be compelling by itself and without further supporting discussion.

In fact, in a footnote, Oliver and Smiley suggest a better example involving a plural description. Up to an unproblematic grammatical transformation their example is as follows:

(4c) Russell and Whitehead, and Hilbert and Bernays are the joint authors of multivolume treatises on logic. (2005: 1063, n. 24)

A moment's reflection shows that the conjunctive analysis that may be available for (4a) does not work for (4c). But there is another problem with (4c) (and with (4a) for that matter): it may receive an ordinary plural analysis, where the predicate is a joint author of multi-volume treatises on logic' is ascribed to the plurality consisting of the four logicians in question. It will be objected that on this analysis the following sentence will also be true:

(4d) Russell and Hilbert, and Whitehead and Bernays are the joint authors of multi-volume treatises on logic.

But the friend of this analysis may be able to accept the truth of (4d) and explain away its apparent incorrectness as a pragmatic rather than semantic phenomenon. (4d) seems incorrect because it is grossly misleading to list the authors in a way that does not reflect the pairs of joint 
authorship. By comparison, the following sentence is arguably true but would be grossly misleading (say when teaching a child):

(4e) The first four letters of the alphabet are 'a', 'c', 'b' and 'd'.

Again, we are not defending this attempt to avoid the superplural; we are just observing that the example (4c) is not convincing without further supporting discussion.

Another class of possible examples of the superplural is due to Landman(1989). Consider the following sentences:

(5a) The cards below seven and the cards from seven up have been separated.

(5b) The cows, the pigs and the sheep have been separated.

But here too a conjunctive analysis may be possible. One option is to use a one-place plural predicate ' $x x$ have been separated' that is true of any plurality of objects that have been separated from the other objects in the universe of discourse. Another option is to use a two-place predicate ' $x x$ have been separated from $y y$ ' and analyse (5a-b) as respectively

(6a) The cards below seven have been separated from the cards from seven up.

(6b) The cows have been separated from the pigs, the cows have been separated from the sheep and the pigs have been separated from the sheep.

For a third attempted example of the superplural, consider the following sentence (inspired by Rosen and Dorr 2002: 172-3, n. 21):

(7) The Beatles and the Rolling Stones gave a joint concert.

The idea is that 'the Beatles' and 'the Rolling Stones' are plural terms, making the subject of (7) superplural. Since the predicate 'gave a joint concert' is non-distributive, (7) does not allow of any kind of conjunctive analysis. But there is a different problem with this attempted example. For it is not clear that the expressions 'the Beatles' and 'the Rolling Stones' actually function as plural terms in (7). Despite being syntactically plural, perhaps these expressions function semantically as singular terms denoting rock groups. If so, the subject of (7) would be an ordinary plural term referring to two rock groups, not a superplural term. We will refer to this style of 
analysis - where an apparent superplural term is analysed as an ordinary plural term referring to a number of groups, classes, sets, events (or some other object in the range of singular variables) - as a partial singularization.

There is some evidence in favour of the partial singularization analysis of (7), which takes the expressions 'the Beatles' and 'the Rolling Stones' to function semantically as singular terms. For (7) can be true in situations where different members of the Beatles are present; (7) could for instance be true even if Ringo Starr had been ill and unable to participate. But it is doubtful that this would be so if 'the Beatles' functioned as a plural term denoting four musicians severally. For instance, it appears false to say that 'Paul, John, George and Ringo gave a concert' in a case where Ringo didn't participate. Is this evidence for a partial singularization analysis of (7) compelling? For our purposes here, we need not take a stand. It suffices for us to observe that this purported example of a superplural term fails to be compelling without further supporting discussion.

We finally turn to a more theoretical approach to the search for superplurals. According to the analysis proposed by linguists Brendan Gillon and Roger Schwarzschild, the interpretation of every plural sentence implicitly involves something analogous to the superplural. Gillon (1992) and Schwarzschild (1996) argue that the interpretation of a sentence containing a plural noun phrase always depends on the choice of a cover, where a cover is characterized as a set of sets whose union is the set of objects denoted by the plural expression. The idea is best explained in terms of an example.

Hammerstein, Rodgers and Hart wrote musicals.

The historical facts are that Hammerstein and Rodgers wrote musicals together, that Rodgers and Hart did so too, but that none of them wrote musicals (either singly or jointly) in any other combination. (8) is thus true with respect to the cover $\{\{$ Hammerstein, Rogers $\},\{$ Rogers, Hart $\}\}$ but not with respect to any other covers. ${ }^{6}$

Of course, the analysis of Gillon and Schwarzschild is based on a set theoretic semantics of plural expressions. But the core idea of their analysis seems to be independent of this set theoretic basis and transposable to a plural framework. When sets are replaced by pluralities, a cover becomes a plurality of pluralities. So if this pluralist adaptation of Gillon and

\footnotetext{
${ }^{6}$ Another example would be 'The soldiers hit the targets', which could be true because one of two soldiers hit targets 1 and 2, while the other hit targets 3, 4 and 5.
} 
Schwarzschild's analysis is right, then superpluralities will be needed for the analysis of ordinary plural sentences.

However, we have at least two reasons to continue our search for superplurals. Firstly, while the analysis of plural sentences proposed by Gillon and Schwarzschild is quite popular in linguistics, it is far from universally accepted (Lasersohn 1995). It would be nice if we could find less controversial examples. Secondly, even if (the above pluralist adaptation of) Gillon and Schwarzschild's analysis is correct, it does not give us everything we would like. For on this analysis, the plural noun phrase Hammerstein, Rodgers and Hart' denotes a plurality, not a superplurality. A superplurality is invoked only when the sentence is interpreted. The whole sentence makes a complex predication, whereby the property expressed by the verbal expression 'wrote musicals' is predicated of each plurality of a certain superplurality. Thus, on this analysis, plural noun phrases do not function as superplural terms, and verbal expressions do not function as superplural predicates. But the semantics of such sentences makes covert appeal to a superplural term and to universal quantification over the pluralities of the superplurality (i.e. the cover) that this term denotes. It would be nice if we could find examples of sentences that involve the superplural in a more explicit way.

\section{Searching for superplurals: our new proposal}

Principle (P) from section 2 suggests a strategy for searching for superplurals in English: look for special multigrade predicates that can take different numbers of plural arguments at the same argument place. If such special multigrade predicates can be found, then reasoning analogous to that leading to principle (P) suggests that these are superplural predicates. Here are two examples.

For the first example, imagine a video game in which any finite number $n$ of teams can play against each other in an $n$-way competition. Then consider the sentences:

(9a) These people and those people play against each other.

(9b) These people, those people and these other people play against each other.

Analogous sentences with greater numbers of plural arguments are obviously possible as well. For the second example, consider the predicate 'overlap' as it applies to pluralities of objects. Assume we are looking at a variety of coloured geometrical figures that are made from different materials and are of different sizes. We can then say that 
(10a) The square things and the blue things overlap

in the sense that there are some things that belong to both pluralities. Likewise, the following sentence may well be true:

(10b) The square things, the blue things and the wooden things overlap.

By reasoning analogous to that leading to principle (P), sentences (9a-b) and (10a-b) all seem to involve superplural predicates, namely ' $x x x$ play against each other' and ' $x x x$ overlap'. Note that we do not claim that the English predicates 'play against each other' and 'overlap' are always superplural; clearly, they often function as ordinary plural predicates. Our claim is just that these predicates can also function superplurally.

We now show that these two examples are immune to the strategies for explaining away the superplural that we encountered in the previous section. We begin with the conjunctive analysis. On the reading that is most natural in the specified context, sentences like (9b), with three or more plural arguments, are not analytically equivalent to any conjunction of atomic sentences based on the two-place predicate ' $x x$ and $y y$ play against each other'. For no conjunction of such claims about two-way competition can imply a claim about $n$-way competition. Likewise, (10b) is not analytically equivalent to a conjunction of atomic sentences based on the two-place plural predicate ' $x x$ overlap $y y$ '. To see this, observe that the following sentence

(11a) The square things overlap the blue things, the blue things overlap the wooden things, and the wooden things overlap the square things

cannot imply (10b), as there are interpretations under which (11a) is true and (10b) is false.

Another attempted analysis of (10b) would be as

(11b) There is a thing that is one of the square things, the blue things and the wooden things.

This in turn could receive a conjunctive analysis as

(11c) There is a thing such that it is one of the square things, it is one of the blue things, and it is one of the wooden things. 
However, this analysis would require 'overlap' to be a defined term, with the effect that (11a) means the same as (11b). But it seems extremely plausible that 'overlap' can be taught to a child as a lexical atom and is in fact primitive. Of course the meanings of the two sentences are closely related. But this does not imply that one is defined in terms of the other. We conclude that our two examples do not allow of any kind of conjunctive analysis.

What about the partial singularization analysis? Unlike expressions such as 'the Beatles' and 'the Rolling Stones', it would be odd to take expressions such as 'these people' and 'those people' to be singular terms denoting, say, groups. ${ }^{7}$ The same goes for expressions such as 'the square things'. This makes a partial singularization analysis of either of our examples unattractive. $^{8}$

What about an ordinary plural analysis of our sentences (9a-b) and (10a-b)? Let ' + ' denote the operation of amalgamating pluralities. One may then propose the following analyses of (9b) and (10b) respectively:

(12) Play-against-each-other(these people + those people + these other people)

Overlap(the square things + the blue things + the wooden things)

But these analyses are easily seen to ascribe incorrect truth-conditions. Consider the case of (10b). Assume the square things, the blue things and the wooden things overlap. Divide all these things into three pluralities that do not overlap: these things, those things and these other things. Now consider the sentence:

(10c) These things, those things and these other things overlap.

On the view in question, (10c) receives an analysis equivalent to that of (10b), namely (13), although (10b) has been assumed to be true, and (10c) false.

\footnotetext{
${ }^{7}$ Landman (1989) might suggest that the plural expressions in (9a) and (9b) denote what he calls 'groups' and models as sets of sets. But this suggestion can be set aside for present purposes. For our goal is to explore the prospects for the superplural on the assumption (now widely shared in philosophy and logic) that a non-singularising interpretation of plurals is correct.

${ }^{8}$ For a further problem, consider the true claim of modern set theory that the ordinals and the cardinals overlap. A partial singularization analysis of this claim would require us to postulate proper classes or other objects capable of 'singularising' pluralities that are too large to form sets. This reintroduces a threat of paradox. (Thanks here to Gabriel Uzquiano.)
} 
Finally, could a purely plural analysis of (9a-b) or (10a-b) be rescued by combining it with Gillon and Schwarzschild's ideas on the use of covers in the interpretation of plural sentences? The answer seems to be negative. To begin with, in sentences like (8), the predicate is applied to each plurality of the superplurality that is associated with the cover in question. So this kind of treatment cannot apply to cases that resist a conjunctive analysis, such as our examples. But even if this problem could be overcome - say by allowing the predicate to apply in a collective way to all the pluralities of the superplurality associated with the cover - another problem would remain. ${ }^{9}$ To see this, consider the sentence:

The things that are square, blue or wooden overlap.

On the analysis in question, the same plurality serves as the subject of (10b) and (14). In both sentences, the square things, the blue things and the wooden things are equally salient and thus provide the same basis for the cover $\{\{$ the square things\}, \{the blue things $\}$, \{the wooden things $\}$ \}. The analysis predicts that (14) should lend itself to the reading that is so natural for (10b), where the predicate is ascribed in an irreducibly collective way to the superplurality associated with the above cover. But this reading is simply not available for (14).

\section{Concluding remarks}

We conclude that (9a-b) and (10a-b) are genuine cases of superplural predications in English, involving a superplural predicate applied to a superplural term. These examples avoid the problematic features of the sentences discussed in section 3. Moreover, they go further than Gillon and Schwarzschild's own examples, even on the assumption that their analysis is correct.

We end with some brief remarks about the broader philosophical significance of our examples. Firstly, if correct, these examples show that superplural terms and predicates are just as legitimate as ordinary plural terms and predicates.

Secondly, many arguments given for the ontological innocence of plural terms can be extended to superplural terms. For instance, sentences such as (9a-b) and (10a-b) no more appear to introduce new ontological commitments than do (2a-c). So if (2a-c) are ontologically innocent, so should be (9a-b). It should be noted, however, that this conditional is compatible with two opposite conclusions: either that both plural and superplural terms are ontologically innocent, or that neither is and the arguments provided for the ontological innocence of ordinary plural terms are flawed. Nothing we have said here bears on which conclusion to draw.

\footnotetext{
${ }^{9}$ Thanks to Barry Schein for this observation.
} 
Thirdly, we have not provided any examples of superplural quantification in ordinary English. But given our examples of superplural sentences in English, and given that a formal logic of superplural quantification has been formulated (Rayo 2006), we have given at least some reason to accept superplural quantification as legitimate..$^{10}$

\author{
University of Bristol \\ Bristol BS8 1TB, UK \\ oystein.linnebo@bris.ac.uk
}

Institut Jean Nicod (EHESS-ENS-CNRS)

75005 Paris, France

david.nicolas@m4x.org

\title{
References
}

Boolos, G. 1984. To be is to be a value of a variable (or to be some values of some variables). Journal of Philosophy 81: 430-49.

Gillon, B. S. 1992. Towards a common semantics for English count and mass nouns. Linguistics and Philosophy 15: 597-639.

Hazen, A. P. 1997. Relations in Lewis's framework without atoms. Analysis 57(4): 243-48.

Landman, F. 1989. Groups I. Linguistics and Philosophy 12: 559-605.

Landman, F. 2000. Events and Plurality. London: Kluwer Academic Publishers.

Lasersohn, P. 1995. Plurality, Conjunction, and Events. London: Kluwer Academic Publishers.

Leonard, H. S. and N. Goodman. 1940. The calculus of individuals and its uses. Journal of Symbolic Logic 5(2): 45-55.

Link, G. 1998. Algebraic Semantics in Language and Philosophy. Stanford: CSLI Publications.

Linnebo, Ø. 2003. Plural quantification exposed. Noûs 37(1): 71-92.

Linnebo, Ø. 2004. Plural quantification. In Stanford Encyclopedia of Philosophy, ed. E. N. Zalta, $\mathrm{URL}=\langle\mathrm{http}: / /$ plato.stanford.edu/entries/pluralquant $/>$

McKay, T. 2006. Plural Predication. Oxford: Clarendon Press.

Nicolas, D. Manuscript. Can mereological sums serve as the semantic values of plurals?

Oliver, A. and T. Smiley. 2004. Multigrade predicates. Mind 113: 609-81.

10 Thanks to Cian Dorr, Alex Oliver, Agustín Rayo, Barry Schein, Philippe Schlenker and Gabriel Uzquiano for discussion and comments on earlier versions. Øystein Linnebo gratefully acknowledges support from the Mind Association for a research fellowship during which this article was written. 
Oliver, A. and T. Smiley. 2005. Plural descriptions and many-valued functions. Mind 114: 103968.

Rayo, A. 2006. Beyond plurals. In Absolute Generality, ed. A. Rayo and G. Uzquiano. Oxford: Oxford University Press.

Rayo, A. and G. Uzquiano. 2006. Absolute Generality. Oxford: Oxford University Press.

Rosen, G. and C. Dorr. 2002. Composition as fiction. In The Blackwell Guide to Metaphysics, ed. R. Gale. Malden: Blackwell. 151-174.

Schein, B. 2006. Plurals. In Handbook of Philosophy of Language, ed. E. Lepore and B. Smith. Oxford: Oxford University Press.

Schwarzschild, R. 1996. Pluralities. London: Kluwer Academic Publishers.

Uzquiano, G. 2004. Plurals and simples. The Monist 87(3): 429-51.

Yi, B.-U. 2005. The logic and meaning of plurals. Part I. Journal of Philosophical Logic 34: 459506. 